Check for updates

Cite this: Chem. Commun., 2018, 54,8466

Received 30th May 2018, Accepted 26th June 2018

DOI: $10.1039 / \mathrm{c} 8 \mathrm{cc} 04316 \mathrm{~g}$

rsc.li/chemcomm

\section{'AND'-based fluorescence scaffold for the detection of ROS/RNS and a second analyte $\dagger$}

\author{
Maria L. Odyniec, (D) $\ddagger^{a}$ Adam C. Sedgwick, (D) $\ddagger^{*^{a}}$ Alexander H. Swan, (D) a \\ Maria Weber, (D) ${ }^{\text {a }}$ T. M. Simon Tang, (D) Jordan E. Gardiner, (D) a Miao Zhang, ${ }^{b}$ \\ Yun-Bao Jiang, (D) ${ }^{b}$ Gabriele Kociok-Kohn, ${ }^{a}$ Robert B. P. Elmes, (D) ${ }^{c}$ \\ Steven D. Bull, (DD ${ }^{* a}$ Xiao-Peng $\mathrm{He}\left(\mathbb{D}{ }^{* d}\right.$ and Tony D. James (D) *ae
}

Traditionally, fluorescence probes have focused on the detection of a single biomarker for a specific process. In this work, we set out to develop a number of fluorescence probes that enable the detection of a chosen analyte in the presence of reactive oxygen/nitrogen species (ROS/RNS). These fluorescence probes when activated result in the formation of the highly fluorescent pink dye, resorufin. Therefore, we have labelled these fluorescent probes as 'Pinkments'. Our first 'Pinkment' was shown to detect biologically relevant concentrations of $\mathrm{ONOO}^{-}$and have an excellent selectivity against other ROS/RNS. Pinkment-OH was developed to provide a core unit which could be easily functionalised to produce a range of 'AND' based fluorescence probes for the detection of ROS/RNS and a second analyte. For proof of concept, we synthesised PinkmentOTBS and Pinkment-OAc. These 'AND'-based probes were successfully shown to detect ROS/RNS and $\mathrm{F}^{-}$or esterase, respectively.

Since the discovery of the first fluorescence-based probe in 1867 , fluorescence probes have revolutionised the understanding of biological systems. ${ }^{1-4}$ Historically, these probes have focused on the detection of a single analyte or biomarker. However, biological systems are complex with more than one chemical species being released/present during any biological processes. For example, glutathione (GSH) accumulates at the

\footnotetext{
${ }^{a}$ Department of Chemistry, University of Bath, Bath, BA2 7AY, UK.

E-mail: t.d.james@bath.ac.uk, s.d.bull@bath.ac.uk

${ }^{b}$ Department of Chemistry, College of Chemistry and Chemical Engineering, the MOE Key Laboratory of Spectrochemical Analysis and Instrumentation, and iChEM, Xiamen University, Xiamen 361005, China

${ }^{c}$ Department of Chemistry, Maynooth University, Maynooth, Co. Kildare, Ireland

${ }^{d}$ Key Laboratory for Advanced Materials \& Feringa Nobel Prize Scientist Joint,

Research Center, East China University of Science and Technology,

130 Meilong Rd., Shanghai 200237, P. R. China

${ }^{e}$ Department of Materials and Life Sciences, Faculty of Science and Technology

Sophia University, 7-1 Kioi-cho, Chiyoda-ku, Tokyo 102-8554, Japan

$\dagger$ Electronic supplementary information (ESI) available. CCDC 1844385. For ESI and crystallographic data in CIF or other electronic format see DOI: 10.1039/ c8cc04316g

\# A. C. S. and M. L. O. contributed equally, A. C. S. - organic synthesis, M. L. O. fluorescence analysis.
}

nucleus during the cell cycle to aid transcription factors binding to $\mathrm{DNA}^{5}$ and the pathological role of $\mathrm{Zn}^{2+}$ is believed to be associated with the glutamate system. ${ }^{6}$ Furthermore, the sensitivity of a cell towards peroxynitrite $\left(\mathrm{ONOO}^{-}\right)$largely depends on the concentration of intracellular GSH. ${ }^{7-10}$ Therefore, in order to further understand cellular functions and the root causes of disease it is important to be able to study biologically important species simultaneously.

Alongside the development of the field of fluorescence probes, the field of molecular logic gates has developed. ${ }^{11}$ Molecular logic gates are molecules that have the ability to bind or react with multiple analytes (input) and turn it into a measurable optical output. Consequently, these attractive molecules are now emerging in the literature demonstrating the ability to simultaneously detect multiple analytes in biological systems. ${ }^{12-21}$ Within our research group, we are interested in developing reaction-based fluorescence probes including 'AND'-based fluorescence probes for the detection of biologically important analytes. ${ }^{2-24}$ Dual responsive ('AND') fluorescence probes require both analytes being present to produce a fluorescence response. In this work, we identified a previously reported boronate-based fluorescence probe developed by Chang et al. PR1, with a free amino group attached (Fig. 1). Boronates have well-known reactivity towards $\mathrm{ONOO}^{-}$and hydrogen peroxide $\left(\mathrm{H}_{2} \mathrm{O}_{2}\right),{ }^{25}$ therefore we believed PR1 could provide a suitable

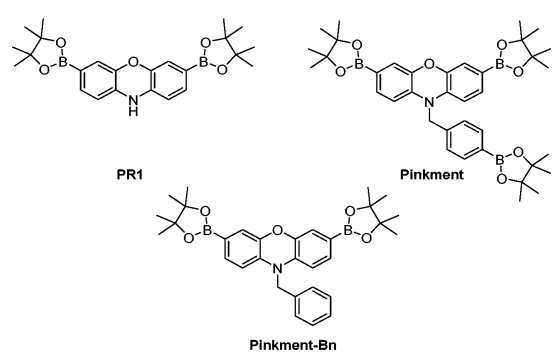

Fig. 1 PR1 and Pinkment fluorescence probes for the detection of reactive oxygen and reactive nitrogen species (ROS/RNS). Pinkment-Bn demonstrates the requirement elimination to produce a free $\mathrm{N}-\mathrm{H}$. 
scaffold for the development of 'AND'-based systems for the detection of ROS/RNS and an second analyte. ${ }^{26}$ In this work, we initially functionalised PR1 with an additional ROS/RNS trigger, benzyl boronic acid ester, which afforded a selective $\mathrm{ONOO}^{-}$ probe known as Pinkment (Fig. 1).

The current literature route to obtain PR1 involves a very low yielding first step (10\% overall yield $7 \%)$, which uses harsh conditions (hydrobromic acid ( $\mathrm{HBr})$ ). ${ }^{26}$ Therefore, we alkylated commercially available phenoxazine using $\mathrm{NaH}$ and 4-bromobenzyl bromide to afford 1 in excellent yield (78\%). 1 was then subsequently dissolved in $\mathrm{CHCl}_{3}$ and NBS was added portion wise to afford dibrominated intermediate 2 in good yield (48\%), which required only trituration (EtOAc) for purification. Lastly, SuzukiMiyaura conditions were applied to 2 using bis(pinacolato)diboron $\left(\mathrm{B}_{2} \mathrm{pin}_{2}\right)$ as a boron transfer agent to furnish Pinkment in $36 \%$ yield (see $\mathrm{ESI} \dagger-$ Scheme S4). In the presence of $\mathrm{ONOO}^{-}$, all three boronates were oxidised on Pinkment, forming the highly fluorescent pink dye, resorufin (see ESI $\dagger$ - Scheme S1) and a large fluorescence increase was observed at $590 \mathrm{~nm}$ (see ESI $\dagger$ - Fig. S1). Pinkment was able to detect biologically relevant concentrations of $\mathrm{ONOO}^{-27,28}$ and displayed excellent selectivity towards $\mathrm{ONOO}^{-}$(see ESI $\dagger$ - Fig. S2-S4). To demonstrate the requirement of an 'eliminating' benzyl group on the free $\mathrm{N}-\mathrm{H}$, Pinkment-Bn (Fig. 1) was synthesised (see ESI $\dagger$ - Scheme S5) and as expected no increase in fluorescence intensity was observed with the addition of $\mathrm{ONOO}^{-}(10 \mu \mathrm{M})$ (see ESI $\dagger-$ Fig. S5).

From these results, we believed we could develop a range of 'AND'-based Pinkment fluorescence probes by altering the functionality on the benzyl group to react with a specific target analyte. To achieve this, we developed a synthesis for Pinkment-OH (Fig. 2), which provides a novel fluorescence core probe that can be functionalised with any chosen reactive chemical trigger for the detection of a chosen analyte in the presence of ROS/RNS (Fig. 2a).

For the synthesis of Pinkment-OH, the phenol of 4-hydroxybenzyl alcohol was selectively piv protected to afford

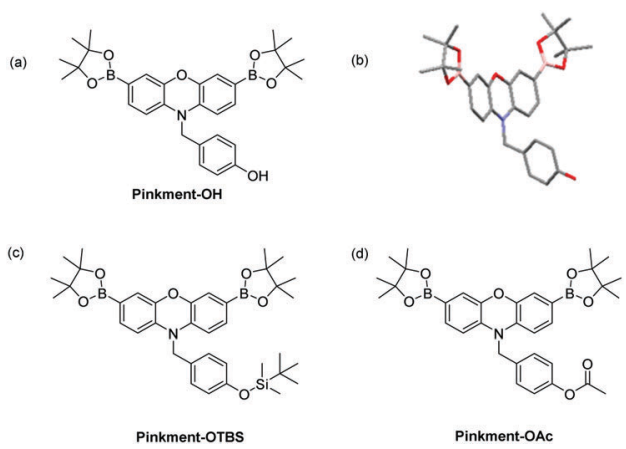

Fig. 2 (a) Pinkment-OH - a core fluorescence unit that enables the synthesis of 'AND' based fluorescence probes for the detection of (ROS/RNS) and a second analyte. (b) Molecular structure of Pinkment-OH with thermal ellipsoids shown at $50 \%$ probability. Hydrogen atoms are omitted for clarity except for the $\mathrm{OH}$ hydrogen atom. (c) Pinkment-OTBS (d) Pinkment-OAc for the detection of ROS/RNS 'AND' fluoride or esterase, respectively. See ESI $\dagger$ - Fig. S4. CCDC 1844385 contain the supplementary crystallographic data for Pinkment-OH. $\dagger$
5 using pivaloyl chloride and $\mathrm{NEt}_{3}$ in DCM. 5 was then converted to its corresponding bromide 6 using $\mathrm{MsCl}$ and $\mathrm{NEt}_{3}$ followed by the addition of LiBr. Phenoxazine was then alkylated with 6 to produce 7 using $\mathrm{NaH}$ and DMF in satisfactory yield (51\%). 7 was then dibrominated using $\mathrm{NBS}$ in $\mathrm{CHCl}_{3}$ to afford 8, which was subsequently deprotected using DIBAL-H to afford 9 in good yield (67\%). The same Suzuki-Miyaura conditions were then applied to furnish Pinkment-OH in excellent yield (83\%) (see ESI $\dagger$ - Scheme S6). To illustrate the stability of Pinkment-OH, an X-ray structure was obtained (Fig. 2b). Interestingly, Pinkment-OH formed dimers via intermolecular hydrogen bonding (see ESI $\dagger$ - Fig. S20).

Pinkment-OH was shown to have a high sensitivity and excellent selectivity towards $\mathrm{ONOO}^{-}$making it suitable for cellular imaging experiments (see ESI $\dagger-$ Fig. S6-S9). As proof of concept for 'AND'-based pinkment sensors, we chose to synthesise Pinkment-OTBS and Pinkment-OAc (Fig. 2c and d), which can be used to detect ROS/RNS and fluoride $\left(\mathrm{F}^{-}\right)$or esterase, respectively.

To afford Pinkment-OTBS, Pinkment-OH was silyl protected using standard silyl protection conditions, however, the reaction was found to be very slow (3 d) and Pinkment-OTBS was isolated in very low yield (11\%) (see ESI $\dagger-$ Scheme S7). We then evaluated the ability of Pinkment-OTBS to detect $\mathrm{F}^{-}$'AND' $\mathrm{ONOO}^{-}$in a buffer solution $\left(52 \% \mathrm{w} / \mathrm{w} \mathrm{MeOH}: \mathrm{H}_{2} \mathrm{O}\right)$. This $\mathrm{MeOH} / \mathrm{H}_{2} \mathrm{O}$ buffer solution was required for the silyl-ether deprotection reaction to proceed effectively. As shown in ESI $\dagger$ - Fig. S10, 100\% PBS produced a much smaller response when both analytes were added, which is consistent with literature reported TBS fluorescence probes. ${ }^{29,30}$ As shown in Fig. 3, addition of tert-butylammonium fluoride (TBAF - source of $\mathrm{F}^{-}$) led to no increase in fluorescence intensity, however, subsequent additions of $\mathrm{ONOO}^{-}(0-20 \mu \mathrm{M})$ led to a significant increase in fluorescence intensity.

To ensure both analytes were required, the addition of TBAF and $\mathrm{ONOO}^{-}$were then repeated in reverse order. Due to the high reactivity of $\mathrm{ONOO}^{-8,31}$ a small increase in fluorescence intensity was observed on addition to Pinkment-OTBS $(20 \mu \mathrm{M})$.

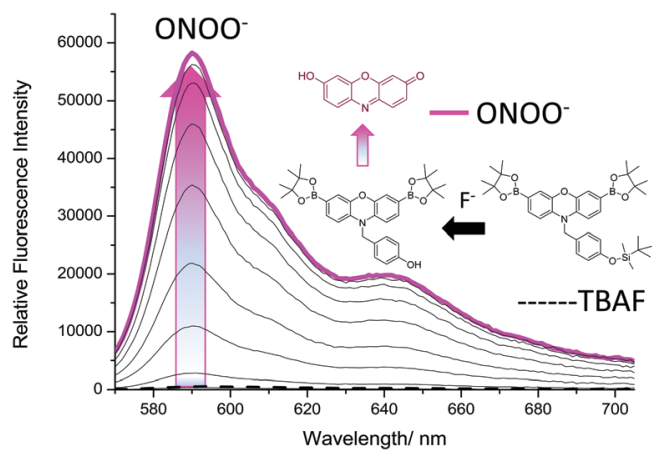

Fig. 3 Fluorescence spectra of Pinkment-OTBS $(0.5 \mu \mathrm{M})$ with addition of TBAF $(10 \mathrm{mM})$ and incubated for $1 \mathrm{~h}$ and then measured. Followed by incremental additions of $\mathrm{ONOO}^{-}(0-20 \mu \mathrm{M})$ The data was obtained in PBS ( $52 \% \mathrm{w} / \mathrm{w} \mathrm{MeOH}: \mathrm{H}_{2} \mathrm{O}$ ), $\mathrm{pH}=8.2$ at $25^{\circ} \mathrm{C}$. $\lambda_{\text {ex }}=545-20 \mathrm{~nm}$. Dashed line represents TBAF $(10 \mathrm{mM})$ addition only. 


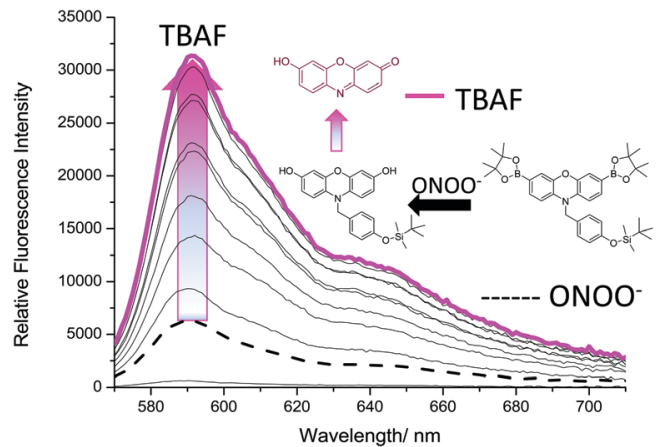

Fig. 4 Fluorescence spectra of Pinkment-OTBS $(0.5 \mu \mathrm{M})$ with the addition of $\mathrm{ONOO}^{-}(20 \mu \mathrm{M})$ followed by incremental additions of TBAF $(0-10 \mathrm{mM})$ measurements were taken after $90 \mathrm{~min}$ of both additions. The data was obtained in PBS $\left(52 \% \mathrm{w} / \mathrm{w} \mathrm{MeOH}: \mathrm{H}_{2} \mathrm{O}\right), \mathrm{pH}=8.2$ at $25^{\circ} \mathrm{C} \cdot \lambda_{\text {ex }}=545-20 \mathrm{~nm}$. Dashed line represents $\mathrm{ONOO}^{-}(2 \mathrm{O} \mu \mathrm{M})$ addition only.

However, like Fig. 3, a large increase in fluorescence intensity was only observed after the subsequent addition of TBAF (0-10 mM) (Fig. 4). As shown in ESI $\dagger$ - Fig. S12 and S13, Pinkment-OTBS displayed an excellent selectivity towards $\mathrm{ONOO}^{-}$against other ROS in the presence of TBAF. Pinkment-OTBS was then screened against other halide sources (TBAB, TBAC and TBAI) in the presence of ONOO $^{-}(20 \mu \mathrm{M})$ see ESI $\dagger$ - Fig. S14. As expected PinkmentOTBS displayed excellent selectivity towards TBAF in the presence of $\mathrm{ONOO}^{-}$.

We then turned our attention towards the synthesis of Pinkment-OAc. Despite the poor reactivity with TBS-Cl, PinkmentOH reacted with AcCl smoothly and produced Pinkment-OAc in excellent yield (71\%) (see ESI $\dagger$ - Scheme S8). Due to the known ability of $\mathrm{ONOO}^{-}$to react with carbonyls, its addition to Pinkment-OAc was avoided (see ESI $\dagger$ - Fig. S15 and S16). Therefore, as proof of concept, we evaluated Pinkment-OAc with $\mathrm{H}_{2} \mathrm{O}_{2}$ 'AND' esterase. As shown in Fig. 5, the addition of porcine liver esterase, PLE $(0.6 \mathrm{U})$ led to no increase in fluorescence intensity. However, subsequent additions of $\mathrm{H}_{2} \mathrm{O}_{2}(0-1 \mathrm{mM})$ led to a large increase in fluorescence intensity.

Again, to ensure that both analytes were required, the concentration of $\mathrm{H}_{2} \mathrm{O}_{2}$ was kept constant $(1 \mathrm{mM})$ and the

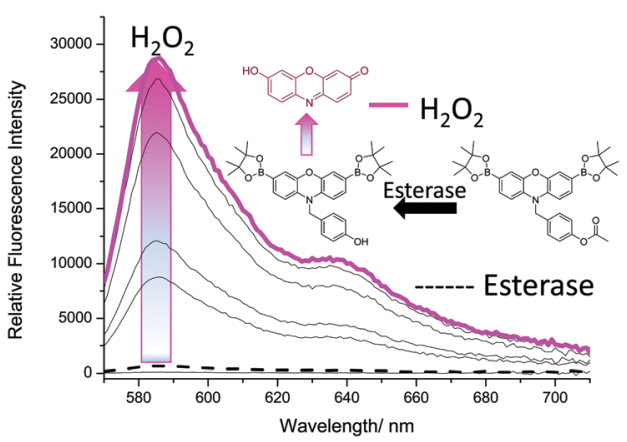

Fig. 5 Fluorescence spectra of Pinkment-OAc $(0.5 \mu \mathrm{M})$ for the incubation (15 $\mathrm{min}$ ) of porcine liver esterase, PLE $(0.6 \mathrm{U})$ followed by incremental additions of $\mathrm{H}_{2} \mathrm{O}_{2}(0-1 \mathrm{mM})$ measurements were taken after $1 \mathrm{~h}$. The data was collected in PBS $\left(100 \% \mathrm{w} / \mathrm{w} \mathrm{H}_{2} \mathrm{O}\right)$ at $\mathrm{pH}=7.4,25^{\circ} \mathrm{C}$. $\lambda_{\text {ex }}=545-20 \mathrm{~nm}$. Dashed line represents esterase $(0.6 \mathrm{U})$ addition only.

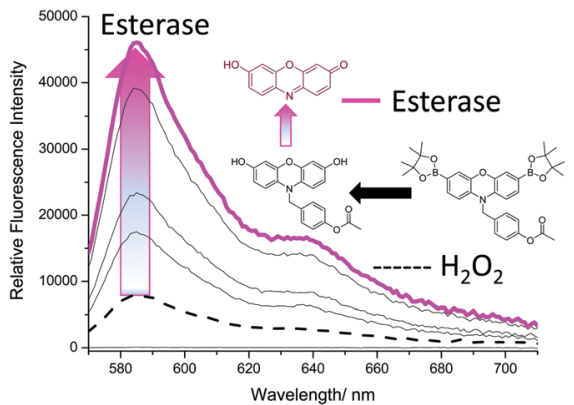

Fig. 6 Fluorescence spectra of Pinkment-OAc $(0.5 \mu \mathrm{M})$ following incubation (15 min) with PLE (0.1-0.6 U) and subsequent addition of $\mathrm{H}_{2} \mathrm{O}_{2}(1 \mathrm{mM})$. The data was collected in PBS buffer $\left(100 \% \mathrm{w} / \mathrm{w} \mathrm{H}_{2} \mathrm{O}\right)$ at $\mathrm{pH}=7.4,25^{\circ} \mathrm{C}$. $\lambda_{\text {ex }}=545-20 \mathrm{~nm}$. Dashed line represents $\mathrm{H}_{2} \mathrm{O}_{2}(1 \mathrm{mM})$ addition only.

amount of PLE was varied. Due to the known ability of $\mathrm{H}_{2} \mathrm{O}_{2}$ to hydrolyse carbonyl containing compounds, it was no surprise that there was a small increase in fluorescence intensity. ${ }^{32,33}$ However, with increasing additions of PLE much larger increases in fluorescence intensity were observed (Fig. 6). Interestingly, concentrations $>0.6 \mathrm{U}$ led to a smaller increase in fluorescence. This is believed to be the result of the excess esterase reacting with the added $\mathrm{H}_{2} \mathrm{O}_{2}$ (see ESI $\dagger$ - Fig. S17).

In summary, several fluorescence-based probes have been synthesised that when activated result in the formation of the highly fluorescent dye, resorufin. As the dye is pink in colour, we have labelled these fluorescent probes as 'pinkments'. The original Pinkment was shown to detect biologically relevant concentrations of $\mathrm{ONOO}^{-}$and have an excellent selectivity against other ROS/RNS making it suitable for cellular imaging experiments. Pinkment provided a suitable platform for the development of 'AND'-based fluorescent probes for the detection of ROS/RNS and another analyte. Pinkment-OH is a core building block that enables easy functionalisation in order to produce a range of 'AND' based fluorescence probes for the detection of (ROS/RNS) and a second analyte. As proof of concept, we developed Pinkment-OTBS and Pinkment-OAc for the detection of ROS/RNS and $\mathrm{F}^{-}$and esterase, respectively. Both Pinkment-OTBS and Pinkment-OAc were demonstrated to be successful 'AND'-based fluorescence probes. However, both probes demonstrated slight reactivity to ROS/RNS alone, due to both silyl ether and acetate functional groups being unstable towards nucleophiles. We are now turning our attention to the attachment of palladium ion $\left(\mathrm{Pd}^{2+}\right)$ and mercury ion $\left(\mathrm{Hg}^{2+}\right)$ reactive triggers, previously developed by Ahn et al. and Koide et al. ${ }^{34,35}$ It is believed that the alkyl ethers will provide the appropriate stability towards ROS/RNS and $\mathrm{Hg}$ and Pd nanoparticles produce ROS in biological systems promoting apoptosis. ${ }^{36-39}$

We would like to thank the EPSRC and the University of Bath for funding for ACS, MLO, JEG for studentships. MW would like to thank the EPSRC for funding (i) EP/L016354/1 and CDT in Sustainable Chemical Technologies. TDJ wishes to thank the Royal Society for a Wolfson Research Merit Award and Sophia University for a visiting professorship. MZ and YBJ were supported by the NSF of China under grants 21435005 and 21521004. XPH wishes to thank the National Natural Science 
Foundation of China (21722801), the Science and Technology Commission of Shanghai Municipality (15540723800) and the Shanghai Rising-Star Program (16QA1401400) for financial support. TDJ, MZ and YBJ thank the Royal Society for funding an International Joint Project (IE121564). NMR characterisation facilities were provided through the Chemical Characterisation and Analysis Facility (CCAF) at the University of Bath (www.bath. ac.uk/ccaf). The EPSRC UK National Mass Spectrometry Facility at Swansea University is thanked for analyses. All data supporting this study are provided as ESI $\dagger$ accompanying this paper.

\section{Conflicts of interest}

No conflicts of interest.

\section{Notes and references}

1 D. Wu, A. C. Sedgwick, T. Gunnlaugsson, E. U. Akkaya, J. Yoon and T. D. James, Chem. Soc. Rev., 2017, 46, 7105-7123.

2 J. Chan, S. C. Dodani and C. J. Chang, Nat. Chem., 2012, 4, 973-984.

3 Y. M. Yang, Q. Zhao, W. Feng and F. Y. Li, Chem. Rev., 2013, 113, 192-270.

4 X. P. He and H. Tian, Chem, 2018, 4, 246-268.

5 J. Markovic, C. Borras, A. Ortega, J. Sastre, J. Vina and F. V. Pallardo, J. Biol. Chem., 2007, 282, 20416-20424.

6 B. Pochwat, G. Nowak and B. Szewczyk, Neural Plast., 2015, 2015, 591563.

7 K. A. Marshall, R. Reist, P. Jenner and B. Halliwell, Free Radical Biol. Med., 1999, 27, 515-520.

8 P. Pacher, J. S. Beckman and L. Liaudet, Physiol. Rev., 2007, 87, 315-424.

9 J. P. Bolanos, S. J. R. Heales, J. M. Land and J. B. Clark, J. Neurochem., 1995, 64, 1965-1972.

10 M. Nakamura, V. H. Thourani, R. S. Ronson, D. A. Velez, X. L. Ma, S. Katzmark, J. Robinson, L. S. Schmarkey, Z. Q. Zhao, N. P. Wang, R. A. Guyton and J. Vinten-Johansen, Circulation, 2000, 102, 332-338.

11 S. Erbas-Cakmak, S. Kolemen, A. C. Sedgwick, T. Gunnlaugsson, T. D. James, J. Yoon and E. U. Akkaya, Chem. Soc. Rev., 2018, 47, 2228-2248.

12 C. Y. Ang, S. Y. Tan, S. J. Wu, Q. Y. Qu, M. F. E. Wong, Z. Luo, P. Z. Li, S. T. Selvan and Y. L. Zhao, J. Mater. Chem. C, 2016, 4, 2761-2774.

13 S. Debieu and A. Romieu, Org. Biomol. Chem., 2015, 13, 10348-10361.

14 G. C. Van de Bittner, C. R. Bertozzi and C. J. Chang, J. Am. Chem. Soc., 2013, 135, 1783-1795.

15 F. B. Yu, P. Li, B. S. Wang and K. L. Han, J. Am. Chem. Soc., 2013, 135, 7674-7680.
16 X. F. Yang, Q. Huang, Y. G. Zhong, Z. Li, H. Li, M. Lowry, J. O. Escobedo and R. M. Strongin, Chem. Sci., 2014, 5, 2177-2183.

17 S. Resa, A. Orte, D. Miguel, J. M. Paredes, V. Puente-Munoz, R. Salto, M. D. Giron, M. J. Ruedas-Rama, J. M. Cuerva, J. M. Alvarez-Pez and L. Crovetto, Chem. - Eur. J., 2015, 21, 14772-14779.

18 X. P. He, X. L. Hu, T. D. James, J. Yoon and H. Tian, Chem. Soc. Rev., 2017, 46, 6687-6696.

19 L. Yu, S. L. Wang, K. Z. Huang, Z. G. Liu, F. Gao and W. B. Zeng, Tetrahedron, 2015, 71, 4679-4706.

20 J. L. Kolanowski, F. Liu and E. J. New, Chem. Soc. Rev., 2018, 47, 195-208.

21 A. Romieu, Org. Biomol. Chem., 2015, 13, 1294-1306.

22 A. C. Sedgwick, H. H. Han, J. E. Gardiner, S. D. Bull, X. P. He and T. D. James, Chem. Commun., 2017, 53, 12822-12825.

23 A. C. Sedgwick, R. S. L. Chapman, J. E. Gardiner, L. R. Peacock, G. Kim, J. Yoon, S. D. Bull and T. D. James, Chem. Commun., 2017, 53, 10441-10443.

24 A. C. Sedgwick, H. H. Han, J. E. Gardiner, S. D. Bull, X. P. He and T. D. James, Chem. Sci., 2018, 9, 3672-3676.

25 A. Sikora, J. Zielonka, M. Lopez, J. Joseph and B. Kalyanaraman, Free Radical Biol. Med., 2009, 47, 1401-1407.

26 E. W. Miller, A. E. Albers, A. Pralle, E. Y. Isacoff and C. J. Chang, J. Am. Chem. Soc., 2005, 127, 16652-16659.

27 X. M. Chen, B. H. Zhou, T. T. Yan, H. Wu, J. H. Feng, H. S. Chen, C. Gao, T. Peng, D. Yang and J. G. Shen, Free Radical Biol. Med., 2018, 117, 158-167.

28 H. Fujigaki, K. Saito, F. Lin, S. Fujigaki, K. Takahashi, B. M. Martin, C. Y. Chen, J. Masuda, J. Kowalak, O. Takikawa, M. Seishima and S. P. Markey, J. Immunol., 2006, 176, 372-379.

29 X. F. Yang, S. J. Ye, Q. Bai and X. Q. Wang, J. Fluoresc., 2007, 17, 81-87.

30 J. Cao, C. C. Zhao, P. Feng, Y. L. Zhang and W. H. Zhu, RSC Adv., 2012, 2, 418-420.

31 D. Yang, Y. C. Tang, J. Chen, X. C. Wang, M. D. Bartberger, K. N. Houk and L. Olson, J. Am. Chem. Soc., 1999, 121, 11976-11983.

32 M. Abo, Y. Urano, K. Hanaoka, T. Terai, T. Komatsu and T. Nagano, J. Am. Chem. Soc., 2011, 133, 10629-10637.

33 J. Yang, X. L. Zhang, P. Yuan, Y. G. Xu, J. Grutzendler, Y. H. Shao, A. Moore and C. Z. Ran, Proc. Natl. Acad. Sci. U. S. A., 2017, 114, 12384-12389.

34 M. Santra, S. K. Ko, I. Shin and K. H. Ahn, Chem. Commun., 2010, 46, 3964-3966.

35 F. L. Song, S. Watanabe, P. E. Floreancig and K. Koide, J. Am. Chem. Soc., 2008, 130, 16460-16461.

36 B. J. Shenker, T. L. Guo and I. M. Shapiro, Environ. Res., 2000, 84, 89-99.

37 A. E. A. Moneim, Neural Regener. Res., 2015, 10, 881-882.

38 A. E. A. Moneim, Metab. Brain Dis., 2015, 30, 935-942.

39 S. Alarifi, D. Ali, S. Alkahtani and R. S. Almeer, Oxid. Med. Cell. Longevity, 2017, DOI: 10.1155/2017/8439098. 